\title{
The Research of Three-phase Boost/Buck-boost DC-AC Inverter
}

\author{
Xiangli Li, Zhaoyang Yan, Yanni Gao, Hanhong Qi \\ Key Lab of Power Electronics for Energy Conservation and Motor Drive of Hebei Province, \\ Yanshan University, Qinhuangdao, China \\ Email: lxl@ysu.edu.cn
}

Received March, 2013

\begin{abstract}
This paper presents a new inverter based on three-phase Boost/Buck-boost single-stage inverter. The basic configuration of the new topology and their fundamental principle are firstly introduced, the method of design double-loop controller and sliding mode controller are clarified, analyzed and compared in the following. Finally the validity and feasibility of the new topology are tested by simulation. The results indicate that regulation of the voltage transfer ratio and output frequency can be realized optionally by the new converter, furthermore the harmonic distortion of waveform is low. So the inherent drawback of low voltage transfer ratio of traditional converter is effectively settled. This study may provide inspiration for further engineering application.
\end{abstract}

Keywords: Three-phase Boost Single-stage Inverter; Three-phase Buck-boost Single-stage inverter; Double-loop Controller; Sliding Mode Controller

\section{Introduction}

As growing in the field of new energy development and utilization, high power density, high reliability, pollution-free and high performance of a new generation of high frequency transformation technology research has important theoretical value and engineering value. Recently, based on the new concept of novel topologies of the DC-AC inverter has attracted more and more attention. Ramón O. Cáceres referred to a boost DC-AC inverter [1]. The new inverter generates an output voltage larger than the dc input one depending on the instantaneous duty cycle. So this property is not found in the traditional VSI, which produces an ac output instantaneous voltage always lower than the dc input. Through the two groups of converter are cooperate, the load voltage can be sine waveform. The topology can reduce the DC source and the inverter needed DC-DC link. So it can reduce the volume, reduce costs and improve efficiency.

The paper present three-phase Boost, Buck-boost single-stage converter [2]. A control strategy for the threephase boost inverter which each Boost is controlled by means of a double-loop regulation scheme that consists of a new inductor current control inner loop and an also new output voltage control outer loop is applied. A control strategy for the three-phase buck-boost inverter in which each buck-boost is controlled by means of a sliding mode controller is applied.

\section{Introduction of the Three-phase Boost/Buck-boost Single- stage Inverter}

\subsection{The Topology of Three-phase Boost Single- Stage Inverter}

The three-phase boost single-stage inverter is shown in Figure 1. In this topology, three boost inverter which driven by three $120^{\circ}$ phase-shift DC-biased sinusoidal reference make the output capacitor voltage changes over the reference voltage to adjust the output voltage of the boost and output voltage is an AC output voltage [3]. The boost DC-AC inverter exhibits several advantages, the most important of which is that it can naturally generate an AC output voltage from a lower DC input voltage in a single-stage power stage.

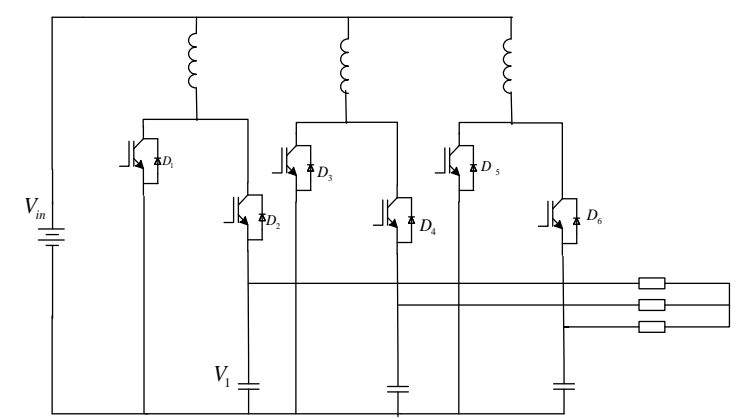

Figure 1. The topology of three-phase Boost. 
Control of the three-phase boost inverter can be achieved by controlling each boost separately. So, analysis one boost inverter can be an example to explain the principle and working process. Using the average concepts, the following voltage relationship for the continuous conduction mode is given by

$$
\frac{V_{1}}{V_{\text {in }}}=\frac{1}{1-d_{1}}
$$

where $d_{1}$ is the duty cycle.

As $V_{1}=V_{d}+V_{01}$ where $V_{d}$ is the capacitor voltage of the DC-biased, where $V_{01}$ is the capacitor voltage of sinusoidal component, have $V_{01}=V_{1}-V_{d}$. According to [4], the single-stage-phase ac output voltage of the boost converter can be compared with the dc input voltage gain is:

$$
\frac{V_{o 1}}{V_{\text {in }}}=\frac{2 d_{1}-G_{m}\left(1-d_{1}\right)}{2\left(1-d_{1}\right)}
$$

where $G_{m}$ is maximum voltage gain $\left(\frac{V_{o p}}{V_{i n}}\right), V_{o p}$ is the output voltage peak-peak of single-stage boost converter.

According to equation (2), the topology of the ac output can be higher or below the intermediate dc voltage.

Three-phase boost single-stage inverter output current of inverter side is positive and negative alternating. The current bidirectional boost dc-dc converter is shown in Figure 2 .

The fundamental principle is: $S_{1}$ and $S_{2}$ are driven by two Complementary signal differ $180^{\circ}$ phase-shifted, $D_{1}$ and $D_{2}$ are the diode parallel. If $S_{1}$ on, $S_{2}$ off, the inductor current direction is positive, the current will be flow through the $S_{1}$; If the inductor current is negative, the current will be flow through the $D_{1}$. If $S_{1}$ off, $S_{2}$ on, the inductor current direction is positive, the current will be flow through the $D_{2}$; otherwise the current will be flow through the $S_{2}$.

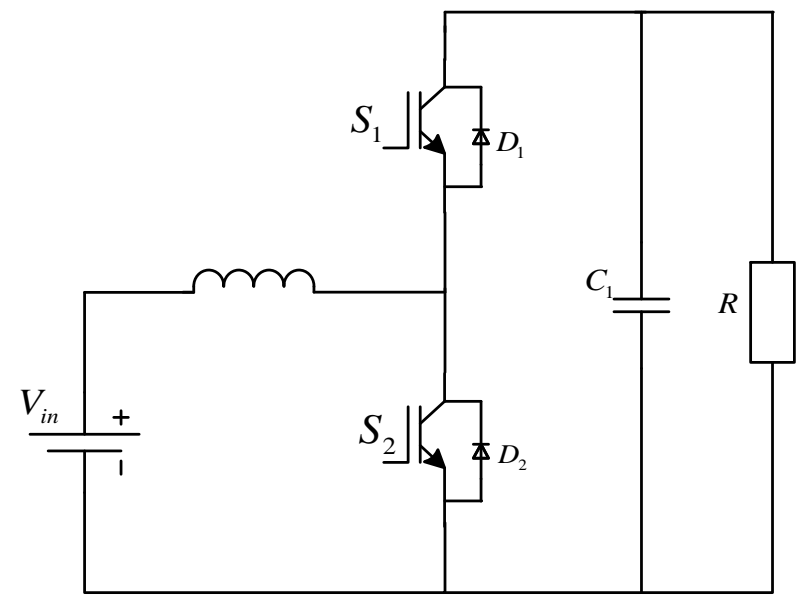

Figure 2. The current bidirectional boost dc-dc converter.

\subsection{The Topology of Three-phase Buck-Boost Single-stage Inverter}

A three-phase buck-boost is similar to a three-phase boost single-stage inverter. A three-phase buck- boost singlestage inverter is shown in Figure 3. Each of three-phase buck-boost single-stage inverter ac output voltage of the boost converter can be compared with the dc input voltage gain is:

$$
\frac{V_{o 1}}{V_{\text {in }}}=\frac{2 d_{1}-G_{m}\left(1-d_{1}\right)}{\left(1-d_{1}\right)}
$$

where the $G_{m}$ is maximum voltage gain $\left(\frac{V_{o p}}{V_{i n}}\right), V_{o p}$ is the output voltage peak-peak of single-stage buck-boost converter.

Three-phase buck-boost single-stage inverter output current of inverter side is positive and negative alternating. The current bidirectional buck-boost dc-dc converter is shown in Figure 4.

The fundamental principle is: $S_{1}$ and $S_{2}$ are driven by two Complementary signal differ $180^{\circ}$ phase-shifted, $D_{1}$ and $D_{2}$ are the diode parallel. If $S_{1}$ on, $S_{2}$ off, the inductor current direction is positive, the current will be flow through the $S_{1}$; If the inductor current is negative, the current will be flow through the $D_{1}$. If $S_{1}$ off,

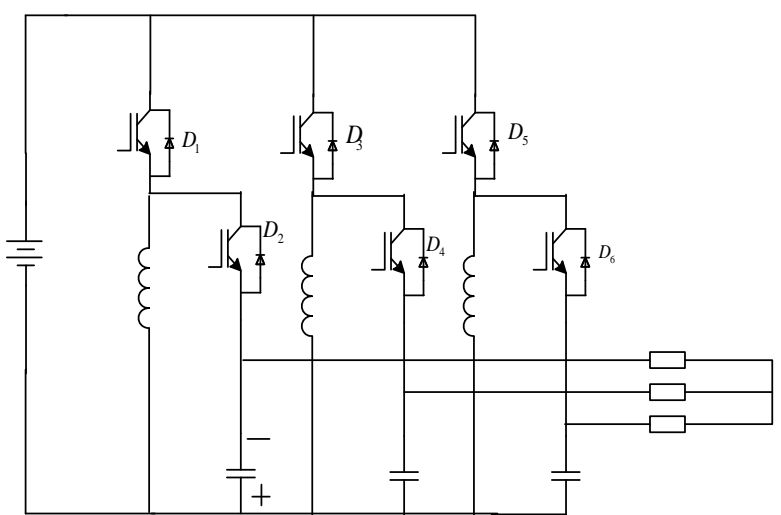

Figure 3. The topology of three-phase buck-boost.

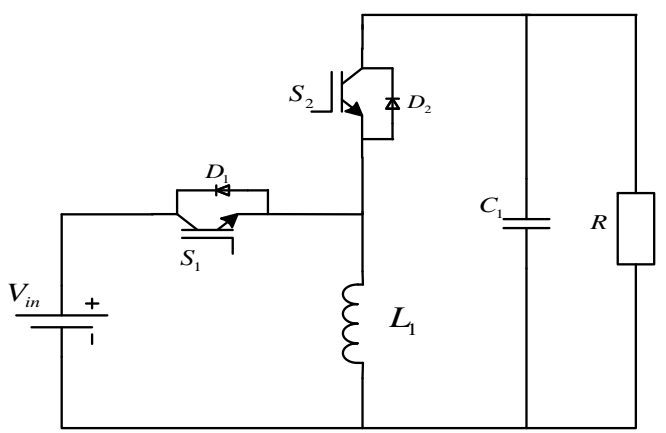

Figure 4. The current bidirectional buck-boost dc-dc converter. 
$S_{2}$ on the inductor current direction is positive, the current will be flow through the $D_{2}$; otherwise the current will be flow through the $S_{2}$.

\subsection{The Compare of the Two Topology}

Although the two converter have different topology and fundamental principle, but from the practical analysis is similar: 1) Three-phase boost and buck-boost singlestage inverter have same number of switches, the complexity of the circuit is similar; 2) Under the condition of the same input voltage, these topology can be through the duty ratios to adjusted the output voltage, to achieve the goal of change the voltage transfer ratio; 3) For the single-stage boost and buck-boost converter, the voltage stress depends on the maximum gain and output voltage and current stress depends on the required current.

\section{The Control Scheme and Compared of the Three-phase Boost/Buck-Boost}

\subsection{Double-loop Control Scheme for the Three Boost}

A double- loop control method [5-8] for the three-phase boost is introduced. For simplify the system analysis, only for a boost converter to introduce.

Firstly, the current inner loop is studied. The mode equations particularized for the boost converter are described as follows:

$$
\begin{gathered}
V_{i n}-V_{L 1}=\left(1-d_{1}\right) V_{o 1} \\
i_{c 1}+i_{o 1}=\left(1-d_{1}\right) i_{L 1}
\end{gathered}
$$

where $V_{01}$ and $i_{c 1}$ are the capacitor voltage and current, $V_{L 1}$ and $i_{L 1}$ are the inductor voltage and current, $i_{o 1}$ is the output current, and $d_{1}$ is the duty cycle.

The inductor and capacitor different equations are:

$$
\begin{gathered}
V_{L 1}=r_{L 1} i_{L 1}+L_{1} \frac{d i_{L 1}}{d_{t}} \\
i_{c 1}+r_{c 1} C_{1} \frac{d_{i_{c 1}}}{d_{t}}=C_{1} \frac{d_{V o 1}}{d_{t}}
\end{gathered}
$$

where $L_{1}, C_{1}, r_{L 1}$ and $r_{c 1}$ are the values for the inductance, capacitance, inductor and capacitor equivalent series resistance.

From equation (4)-(7), the following expression can be obtained, in which internal resistance have been neglected:

$$
\left(V_{\text {in }}-L_{1} \frac{d i_{L 1}}{d_{t}}\right) i_{L 1}=i_{o 1}+C_{1} \frac{d_{V o 1}}{d_{t}}
$$

The equation (8) shows that boost converter has nonlinear relationship between different variables. So designing consistency to the requirements of the boost inverter accurate, stable and suitable for various complex conditions of the controller is very difficult. A control strategy for the three-phase boost inverter in which each boost is controlled by means of a double-loop regulation scheme is shown Figure 5.

The current control loop is defined by equation (4) and equation (6). If choosing the duty cycle to the controller output, the controller is variable and the plant seen by the controller would exhibit a variable gain caused by the variable output voltage $V_{01}$. Therefore, the control strategy of the inductor current feedback value compared with the reference value to control can replace equation (6) with PI controller. The duty cycle $d_{1}$ is then obtained by means of the following expression, in which $V_{\text {Lref }}$ is the controller output

$$
1-d_{1}=\frac{V_{\text {in }}-V_{\text {Lref }}}{V_{01}}
$$

The cancellation of the input voltage influence acts as a feed-forward control. This cancellation would not be required if the current loop bandwidth is much faster than the input voltage.

Concerning the output voltage loop which is introduced in Figure 6, is now defined by equation (5) equation (7). The design of the control structure for the output voltage is based on the same philosophy as the current loop. If the control variable are now the current reference $\left(i_{\text {Lref }}\right)$ for the inner loop, the plant seen by the controller would show again a variable gain caused by the term $1-d_{1}$. Therefore, the capacitor current $\left(i_{c}\right)$ is now proposed to be the control variable, replace equation (7)with PI controller from the equation (5), the calculation of the current reference from the use of duty cycle $\left(d_{1}\right)$,which appears inside the term $1-d_{1}$ as shown in equation (5), However, the calculation of duty cycle $\left(d_{1}\right)$ is provided by the inner current loop, and its use in the current reference calculation would cause a coupling between both inner and outer control loops that could

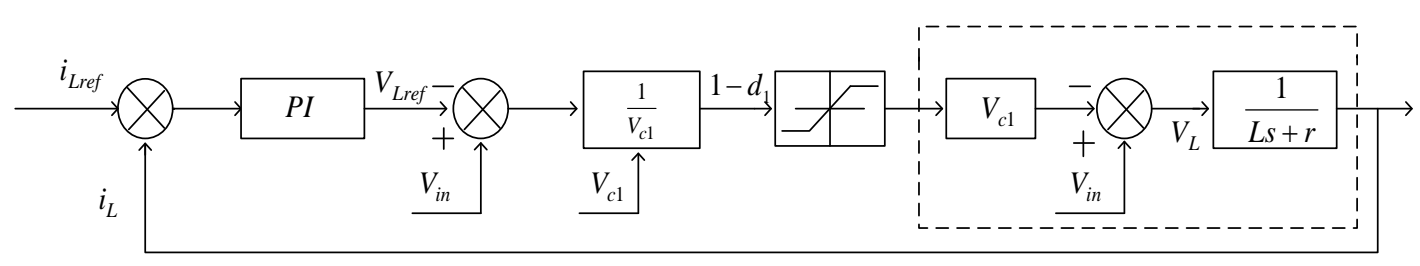

Figure 5. Proposed current control loop. 


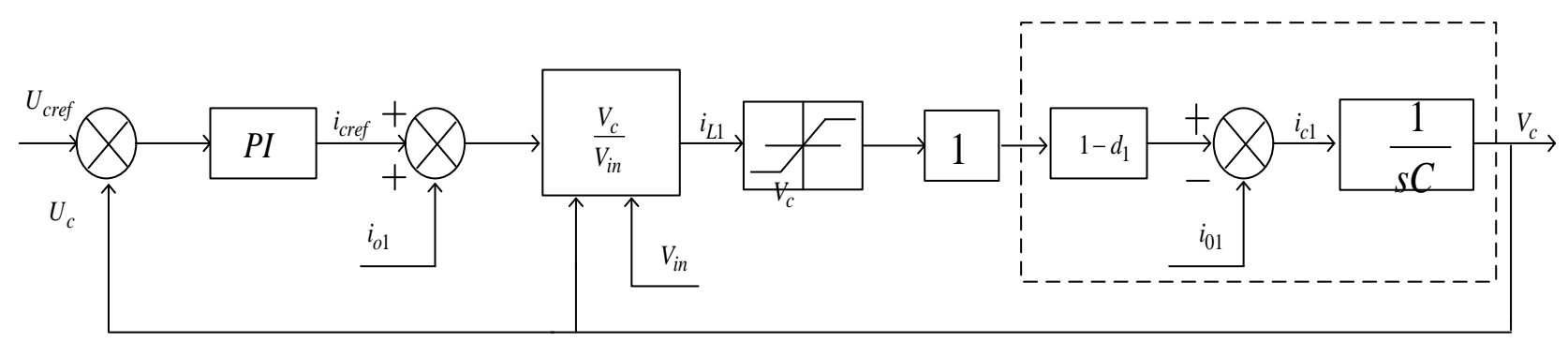

Figure 6. Proposed output voltage control loop.

make the system unstable. Using the average mode, boost converter is

$$
1-d_{1}=\frac{V_{\text {in }}}{V_{01}}
$$

Therefore, the proposed output voltage control loop can also be seen as the result of compensating the plant variable gain (defined by $1-d_{1}$ ) with $\frac{V_{i n}}{V_{o 1}}$ instead, the current reference is then given by the following expression

$$
i_{\text {Lref }}=\frac{i_{c 1}+i_{01}}{1-d_{1}}=\frac{V_{\text {in }}}{V_{01}}\left(i_{c 1}+i_{01}\right)
$$

\subsection{Sliding Mode Controller Analysis}

As for the three-phase buck-boost to introduce the sliding control method. For simplify the analysis, only for a buck-boost converter to introduce [9].

For the purpose of optimizing the buck-boost inverter dynamics, while ensuring correct operation in any working condition, a sliding mode control $[10,11]$ is more feasible approach.

Control of the three-phase buck-boost single-stage inverter by controlling each boost converter. The fundamental principle is shown in Figure 7.

The sliding mode controller make the converter output voltage track the reference signal as precisely as possible. For the current bidirectional dc-dc converter, the statespace molding of the equivalent circuit with state variables $i_{L 1}$ and $V_{1}$ is given by

$$
\left(\begin{array}{c}
\frac{d i_{L 1}}{d t} \\
\frac{d V_{1}}{d t}
\end{array}\right)=\left(\begin{array}{cc}
\frac{-1}{L_{1}} & 0 \\
\frac{-1}{R C_{1}} & \frac{1}{C_{1}}
\end{array}\right) \frac{1}{C_{1}}\left(\begin{array}{c}
i_{L 1} \\
V_{1}
\end{array}\right)+\left(\begin{array}{c}
\frac{V_{1}}{L_{1}} \\
0
\end{array}\right) \gamma+\left(\begin{array}{c}
0 \\
\frac{V_{i n}}{L_{1}}
\end{array}\right)
$$

where $L_{1}$ and $C_{1}$ are the inductor and capacitance; $R$ is a load; $\gamma$ is the status of the switches, defined

$$
\gamma=\left\{\begin{array}{lll}
1 & S_{1} & \text { on } S_{2} \text { off } \\
0 & S_{1} & \text { off } S_{2}
\end{array}\right.
$$

When good transient response of the output voltage is needed, a sliding surface equation in the state space, expressed by a linear combination of the feedback current error, and is the feedback voltage error, can be given

$$
S\left(i_{L 1}, V_{1}\right)=K_{1}\left(i_{L 1}-i_{\text {Lref }}\right)+K_{2}\left(V_{1}-V_{\text {ref }}\right)=0
$$

where coefficients $K_{1}$ and $K_{2}$ are proper gains, the choice must satisfy the existence condition of sliding mode

$$
\begin{cases}\dot{S(x)}<0 & \text { if } S(x)>0 \\ \dot{S(x)}>0 & \text { if } S(x)<0\end{cases}
$$

Sliding mode control is obtained by means of the following feedback control strategy, which relates to the status of the switches with the value of $S(x)$ :

$$
\gamma= \begin{cases}0 & \text { for } S(x)>0 \\ 1 & \text { for } S(x)<0\end{cases}
$$

Compared the equation (12)-equation (16), obtained

$$
\begin{gathered}
K_{1}\left(\frac{R i_{\text {Lref }}-v_{\text {ref }}}{C R}\right)+K_{2}\left(-\frac{v_{\text {ref }}}{L}\right)<0 \\
K_{1}\left(\frac{-v_{\text {ref }}}{C R}\right)+K_{2}\left(\frac{V_{\text {in }}}{L}\right)>0
\end{gathered}
$$

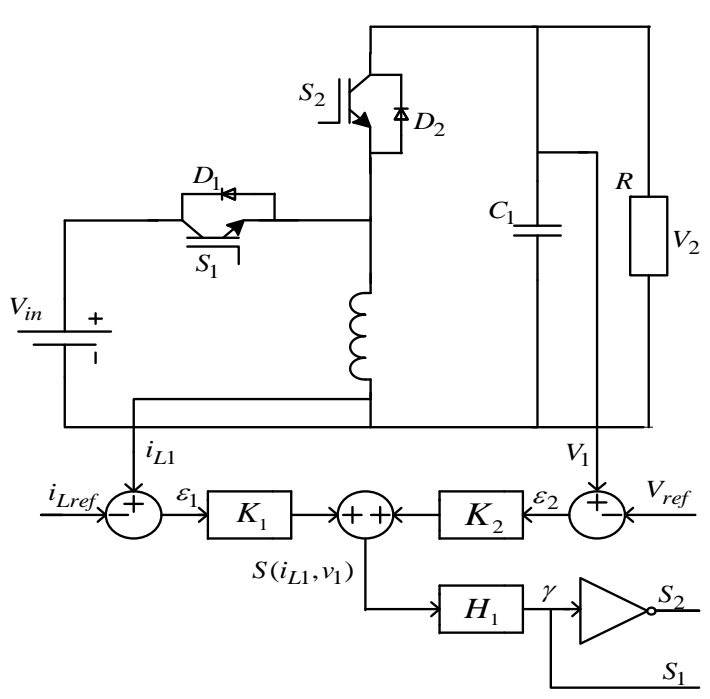

Figure 7. Sliding mode controller scheme. 
If the sliding mode exists, the system behavior is completely determined by coefficients $K_{1}$ and $K_{2}$. It is determines the system response, stability and robustness.

The sliding mode function $S(x)$ is applied to a hysteresis comparator $\left(H_{1}\right)$, produced by the switch control signal $(\gamma)$ in the power switch $S_{1}$ and $S_{2}$. By adjusted $i_{L 1}$ and $V_{1}$ make the $S(x)=0$, so as to realize the accurate tracking of output voltage of the reference signal. In addition, the inductor current is related to the load, the reference value is difficult to determine. Therefore, in practical applications, the inductor current feedback by a high-pass filter, take its high-frequency component to replace the inductor current error, so only need to control the high frequency component of the inductor current.

\section{The Analysis of Simulation}

\subsection{The Result of Simulation}

The simulation results are given assuming the threephase input voltage source, power switch, elements such as inductance and capacitance ideal. The prototype inverter parameters and specification are: input voltage $V_{\text {in }}=48 \mathrm{~V}$, switching frequency $20 \mathrm{KHz}$, inductor $L_{1}=$ $L_{2}=L_{3}=0.13 m H$, three-phase load $R_{1}=R_{2}=R_{3}=$ $32 \Omega$, capacitance $C_{1}=C_{2}=C_{3}=54 u F$, the output frequency is $50 \mathrm{~Hz}$, sliding mode controller coefficients $K_{1}=0.25, K_{2}=0.54$; double-loop control scheme for each Boost are a current loop bandwidth close to $2 \mathrm{KHz}$ and a voltage loop bandwidth of about $800 \mathrm{~Hz}$,both phase margins of $50^{\circ}$.

The contrast analysis diagrams are the three-phase boost double-loop control and three-phase buck-boost sliding mode control of load voltage:

The contrast analyses are three-phase boost doubleloop control and sliding mode control of load FFT:

The contrast analyses are the three-phase boost double- loop control and three-phase buck-boost sliding mode control of capacitance voltage:
The contrast analyses are the three-phase Boost double-loop control and three-phase buck-boost sliding mode control of inductor current:

Three-phase buck-boost sliding surface of the sliding mode control:

Three-phase boost single-stage inverter load sharp reduction in $0.05 \mathrm{~s}$, the simulation waveform graph is shown below:

\subsection{The Simulation Results Analysis}

1) Three-phase boost/buck-boost single-stage inverter indicates that regulation of the voltage transfer ratio can be realized optionally and the output voltage can be accurately tracked according to the reference given by the change; 2) As can be seen from the Figure 8 and Figure $\mathbf{9}$ the harmonic distortion of the output voltage waveform for three-phase symmetrical sinusoidal wave is low; 3) From Figure 8 can be seen that the double-loop control, without overshoot system into a steady state quickly. From Figure 9 can be seen sliding mode control of the load voltage startup performance is poorer, before into the sliding mode surface ,the system has overshoot, there is a lot of impulse voltage, and power is not enough; 4) The double-loop control is the direct control of the current and it has strong robustness to external interference. The buck-boost inverter capacitor voltage stress is lower than the boost inverter, so the switching loss of the former is smaller than the latter, which adopts the doubleloop control of output harmonic is smaller than using sliding mode control of output harmonic, as shown in Figure 10 the harmonic is $0.6 \%$, and in Figure 11, the harmonic is $2.05 \%$; 5) Compared with double-loop control, sliding mode control has better tracking. Sliding mode control of the feedback voltage is almost consistent and a given voltage (155.5 V) for $155.4 \mathrm{~V}$, and the feedback voltage is $156 \mathrm{~V}$ in the double-loop control; 6) Figure 12 and Figure 13 shows the output capacitor voltage has dc-biased.

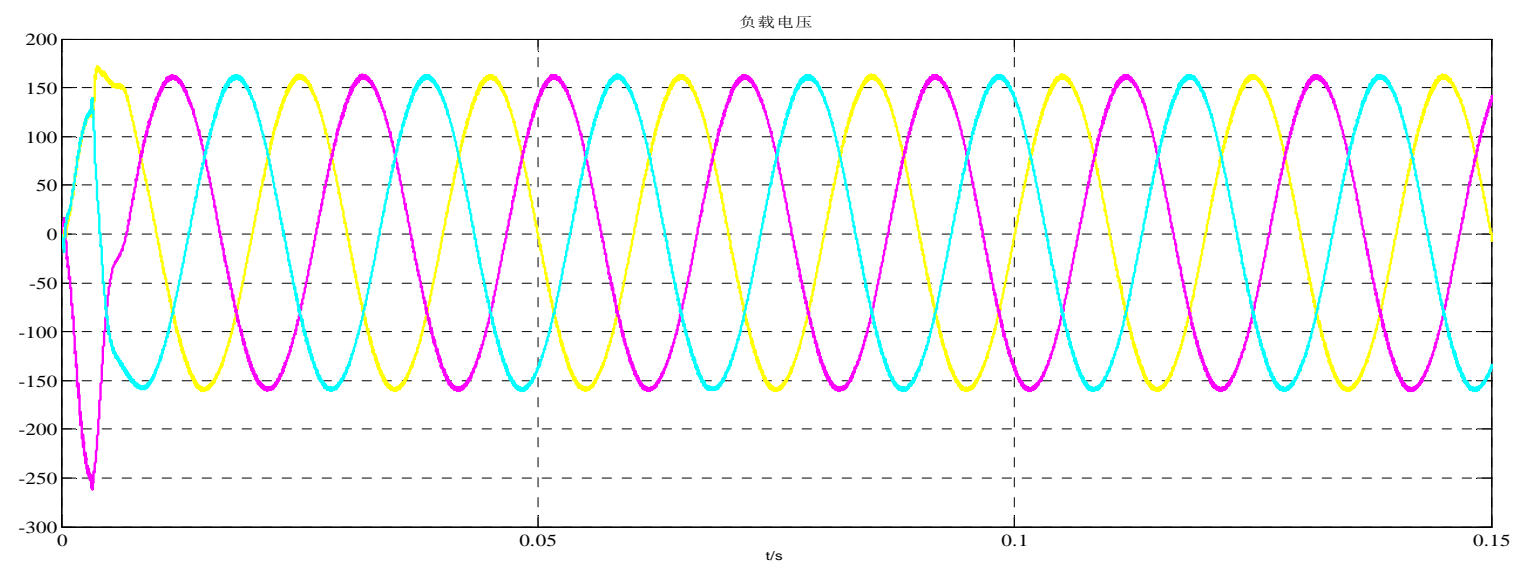

Figure 8. Three-phase boost double-loop control of the load. 


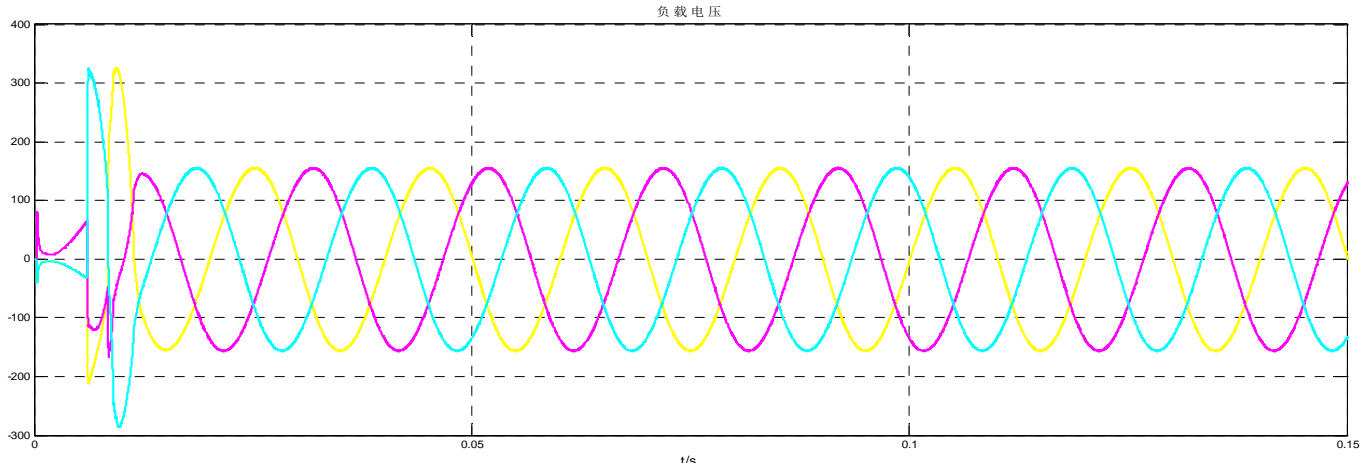

Figrue 9. Three-phase buck-boost sliding mode control of the load voltage.

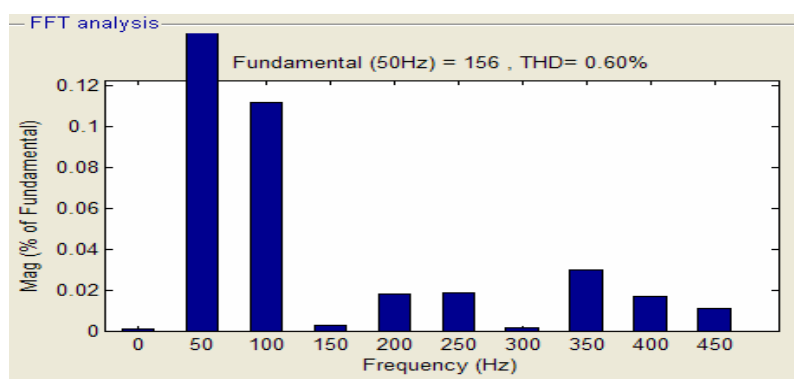

Figure 10. Three-phase boost double-loop control of the load FFT.

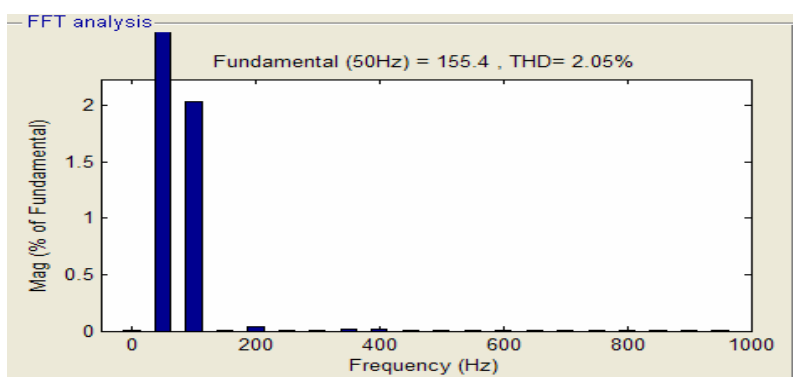

Figure 11. Three-phase buck-boost sliding mode control of the load FFT.

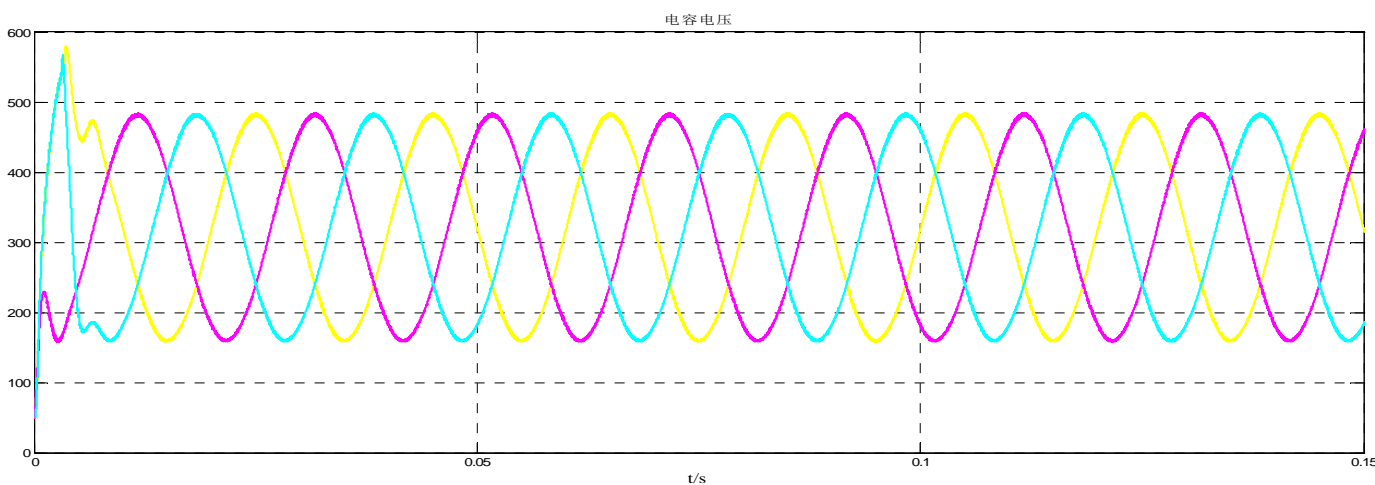

Figure 12. Three-phase boost double-loop control of the capacitance voltage.

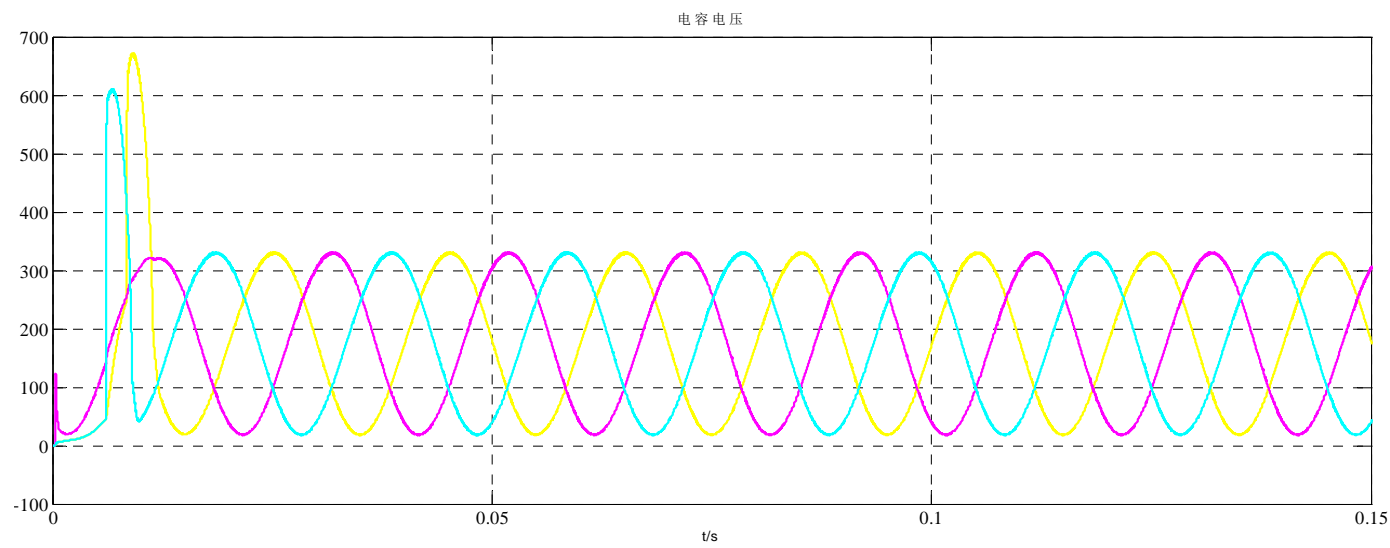

Figure 13. Three-phase buck-boost sliding mode control of the capacitance voltage. 


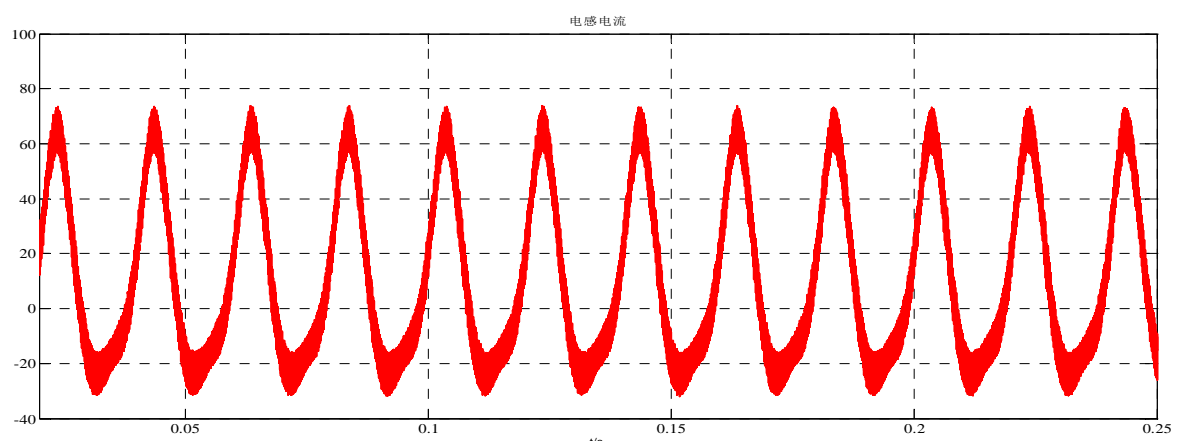

Figure 14. Three-phase Boost double-loop control of the inductor current.

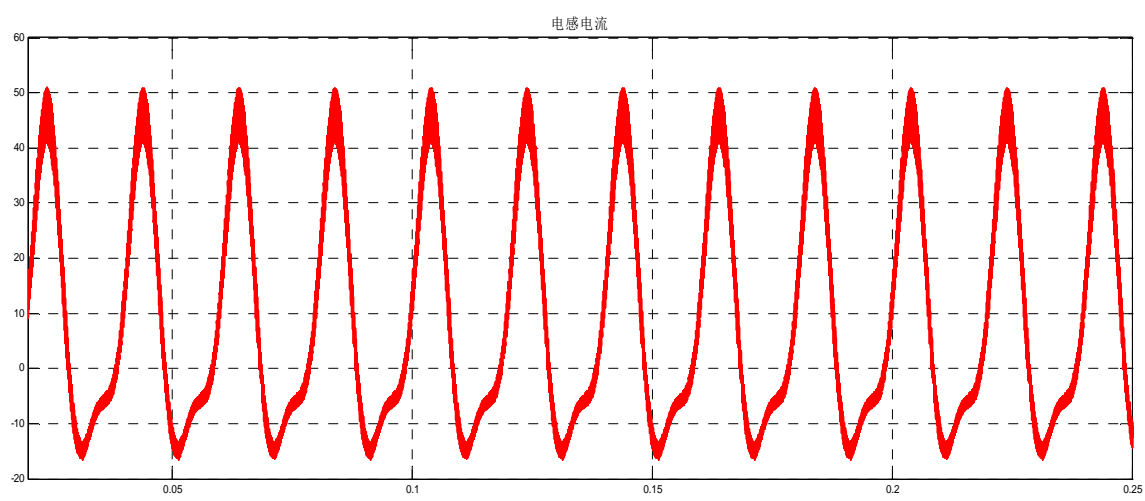

Figure 15. Three-phase Buck-boost sliding mode control of the inductor current.

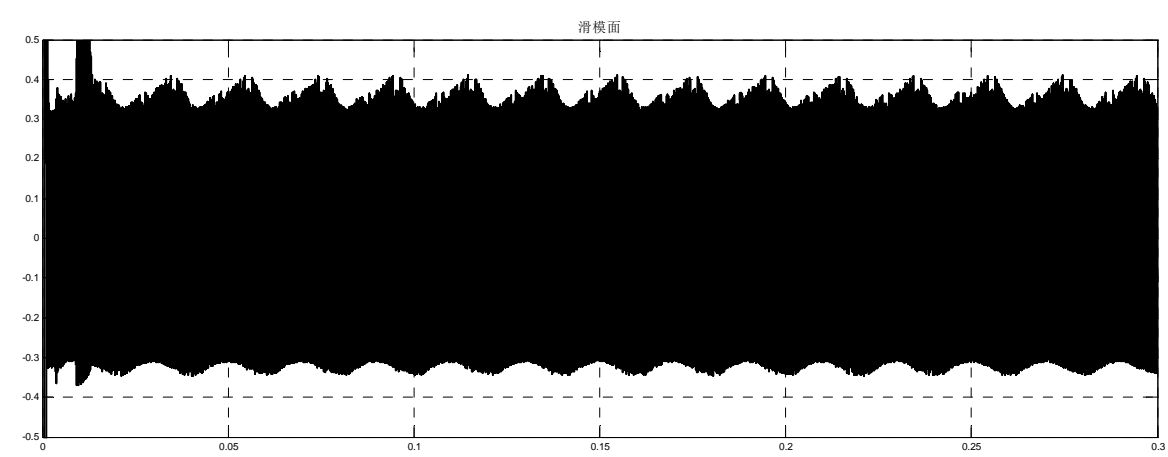

Figure 16. Three-phase Buck-boost sliding mode control of sliding surface.

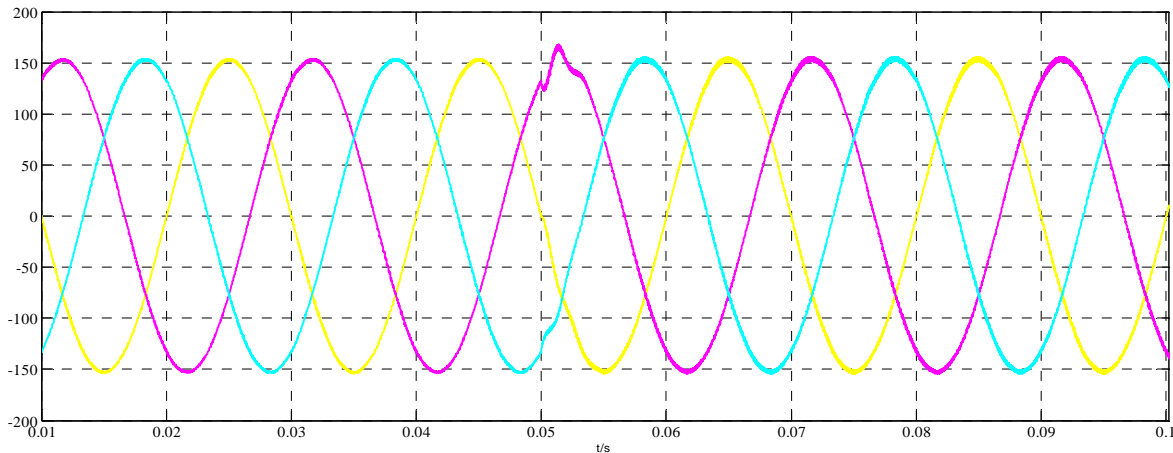

Figure 17. Three-phase boost double-loop control of the load sharp reduction voltage. 


\section{Conclusions}

The paper deals with the topology and comparison of three-phase boost, buck-boost single-stage inverter. A control strategy for the three-phase buck-boost inverter has been proposed in this project in which buck-boost converters of the buck-boost inverter are controlled by means of a sliding mode control, while the three-phase boost inverter in which each boost is controlled are by means of a double-loop control scheme that consists of a new inductor current control inner loop and a new output voltage control outer loop. These loops include several compensations that make possible an accurate control of the boost converters. In addition, some feed-forward regulations are also designed to make the system highly robust for both of input voltage and output current disturbances. The simulation result shows that regulation of the voltage transfer ratio and output frequency can be realized optionally by the new converter, furthermore the harmonic distortions of waveform is low and have the advantage, such as robustness, good tracking performance. These new inverter is intended to be used in uninterruptible power supply (UPS) and ac driver systems design whenever an ac voltage larger than the dc link voltage is needed, with no need of a second power conversion stage.

\section{Acknowledgements}

This work was supported by key programs of NSFC(50837003), and by the Program of the Science and Technology Foundation of Hebei province of China (11213943), and also be supported by the Doctor Research Fund of Yanshan University(No.B549).

\section{REFERENCES}

[1] R. O. Cáceres and I. Barbi, “A Boost DC-AC Converter: Analysis, Design, and Experimentation,” IEEE, Transactions on Power Electronics 1999, Vol. 14, pp. 134-141.
[2] Z. X. Yan, J. X. Li, W. Zhang, Q. Zhang, Y. N. Zheng and W. Y. Wu, "Topology Family and the Simulation of “ BOOK” Differential Single-stage Stage Inverter," IEEE, 2010. doi:10.1109/63.737601

[3] Z. Y. Yan, J. X. Li, Y. N. Zheng and W. Y. Wu, "Research of Double-Boost Single-stage Stage DC/AC Converter based on SPWM,” Vol. 47, No. 9, 2007, pp. 17-19.

[4] N. Vazquez, D. Cones, C. Hemalldez, et a1., "A New Nonlinear Control Strategy for the Boost Inverter," IEEE International power Electronics Conference, Mexico, 2003.

[5] P. Sanchis, A. U. E. Gubía and L. Marroyo, "Boost DC-AC Inverter: A New Control Strategy,” IEEE Transactions on Power Electronics, Vol. 20, No. 02, 2005, pp. 343-353. doi:10.1109/TPEL.2004.843000

[6] B. Kalaivani, V. K. Chinniyan and J. Jerome, “A Novel Control Strategy for the Boost DC-AC Inverter," India International Conference on Power Electronics, 2006, pp. 341-344.

[7] R. Cáceres, R. Rojas and O. Camacho, "Robust PID Control of a Buck-Boost DC-AC Converter,” IEEE, 1998, pp. 180-185.

[8] P. Sanchis, A. Ursua, E. Gubia and L. Marroyo, "BuckBoost DC-AC inverter: Proposal for a New Control Strategy," 35th Annual IEEE Power Electronics Specialists Conference, 2004, pp. 3994-3998.

[9] Z. Q. Cai, F. Hong and Wang, "Research on a Single-stage-stage Buck/Boost Inverter,” Power Supply Technologies and Application, Vol. 11, No. 4, 2008, pp. 43-47.

[10] H. Ma, T. Zhang and S. L. han, “Analysis and Design of Sliding Mode Control for Novel Buck Inverter," Transactions of China Electrotechnical Society, 2005, Vol. 20, No. 7, pp. 50-56.

[11] J. Chen, "The Research of DC-AC Inverter Based on Sliding Mode Control,” Master’s Thesis, University,2003.

[12] J. L. Zhu, Z. Yue, X. P. Zhang, S. S. Liu and S. W. Liu, "A Study of BMC and BBMC with High Volt- age Transfer Ratio. Proceedings of the CSEE,” 2007, Vol. 27, No. 16, pp. $85-91$ 